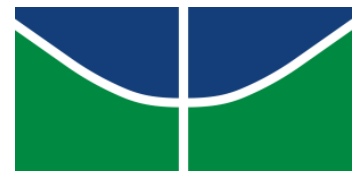

Universidade de Brasília

Departamento de História

\title{
O pensamento Pan-africano na contemporaneidade $O$ caso da Agenda 2063
}

\section{Harlan Gelson Rodrigues dos Santos}

Artigo apresentado como requisito parcial para obtenção do título de licenciado em História

Orientador: Professor Doutor Anderson Ribeiro Oliva 


\title{
Resumo
}

O objetivo deste artigo é analisar a continuidade e influência do pensamento Pan-africano de teóricos como Kwame Nkrumah, W.E.B. DuBois e George Padmore na África contemporânea. Será feita uma análise da trajetória histórica do movimento, as críticas recebidas, as tentativas de integração dos países africanos baseadas no movimento e como ele se manifesta no presente.

Palavras-chave: Pan-africanismo, integração africana, Agenda 2063

\begin{abstract}
The purpose of this paper is to analyze the continuity and influence of Pan-african thinking by theorists such as Kwame Nkrumah, W.E.B. DuBois and George Padmore in contemporary Africa. An analysis will be made of the historical trajectory of the movement, the criticism it received, the attempts at integration of african countries based on the movement and how it manifests itself in the present.
\end{abstract}

Keywords: Pan-africanism, African integration, Agenda 2063 


\section{INTRODUÇÃO}

A segunda metade da década de 1950 é um momento-chave para todo o continente africano. As independências de vários países, as quais, até poucos anos antes, eram vistas como pouco prováveis no futuro próximo, geraram grandes expectativas para o futuro da África e do mundo. Uma das independências mais importantes para o continente foi a de Gana, antiga Costa do Ouro, em 1957, que introduziria o conceito de partido de massas na África. Por meio de um movimento que contava com ampla participação popular, baseado na desobediência civil, liderada por Kwame Nkrumah, Gana se libertou dos britânicos se tornando o primeiro país da África Subsaariana a obter tal feito no pós-Segunda Guerra (KIRK-GREENE, 1986, p. 30).

O processo colonial em Gana e as necessidades da administração britânica dotaram o país de características que o tornavam bastante único no contexto das colônias africanas. Apesar de insuficiente e estritamente ligado às necessidades econômicas e administrativas dos britânicos, contava com o melhor sistema de saúde e educação, maior proporção de pessoas com nível superior, e uma numerosa burguesia nacional, vários elementos que explicam o seu pioneirismo na independência. No entanto, um dos principais fatores que revelam esse protagonismo foi a ação de um dos mais conhecidos líderes políticos africanos: Kwame Nkrumah. Ativista do Pan-africanismo, ele seria uma peça central na mudança de condução da luta pela independência de Gana, a partir de sua volta para o país, na década de 1940. Inspirado no movimento pacifista liderado por Gandhi, que obteria a independência da Índia em 1947, Nkrumah adotou vários dos princípios de desobediência civil empregados pelos indianos. Ele utilizaria os novos recursos obtidos com a sua chegada ao poder para propagar os ideais Pan-africanos, principalmente em relação aos países ainda não independentes.

Embora não deva ser reduzido às conferências iniciadas no século $\mathrm{XX}$, é com a conferência de Londres, em 1900, que o movimento Pan-africano se torna mais concreto e organizado. Os participantes buscavam obter ganhos majoritariamente sociais e só posteriormente, a conferência de 1945, em Manchester, seria o marco da inclusão de pautas mais políticas. A partir da conferência de Acra, em 1958, o Pan-africanismo ganha mais 
corpo, e se torna nacionalista. Para Nkrumah, a conferência seria um marco na forma como o mundo olhava a África, já que, agora, os assuntos africanos eram discutidos por africanos e na África (NKRUMAH, 1963, p. 136).

Na definição de Guy Martin, exposta na $13^{\circ}$ Assembleia Geral da CODESRIA, em 2011, a unificação política de todos os Estados africanos seria a "meta síntese" do Pan-africanismo:

\begin{abstract}
O Pan-africanismo é um ideal e movimento cultural, político e econômico concebido para reagrupar e mobilizar os africanos na África e na diáspora contra a discriminação racial, domínio e opressão estrangeiros, bem como a exploração econômica, possuindo três dimensões diferentes: cultural, política e econômica. Culturalmente, visa reivindicar a herança, a história, a cultura, as tradições e os valores de África. Politicamente, o Pan-africanismo está ligado à luta de independência. Economicamente, o Pan-africanismo está ligado à luta contra $\mathrm{o}$ imperialismo, colonialismo, neocolonialismo e globalização, ou seja, essencialmente uma luta contra as estratégias de "dividir e governar" que resultaram na balcanização da África (MARTIN, 2011, p. 2-3, adaptado).
\end{abstract}

Em seu ensaio Africa Must Unite ${ }^{1}$, de 1963, Nkrumah elabora uma sequência de motivos que fariam com que a união continental fosse requisito para a mudança completa no status das novas nações africanas. Para ele, o socialismo era o instrumento para alcançar um objetivo além das independências individuais das então colônias africanas: a união Pan-africana. Para o sucesso desse objetivo, se fazia necessário um partido de massas, o qual se concretizou com a fundação do Convention People’s Party (CPP), em 1949. Na visão de Nkrumah, o partido teria o papel de lutar contra as elites locais que serviam de intermediários entre a administração colonial e a população. Representando os interesses de toda a "nação", o CPP seria o líder natural da implantação do socialismo. Mais do que ser apenas contra o colonialismo, ele era contrário à ideia de libertação gradual, defendendo o corte imediato dos laços políticos com as metrópoles (NKRUMAH, 1963, p. 55-57). Isso permitia uma generalização extrema de seu discurso, dando ênfase aos nacionalismos africanos com a intenção de formar uma identidade nacional homogênea em oposição à dominação imperialista e à oposição nacional colaboracionista.

O ideal Pan-africano evoluiu consideravelmente desde o período das conferências realizadas no exterior. Em 1963, sob influência direta de Kwame Nkrumah e Haile Selassie, foi criada em Adis Abeba a Organização da União Africana (OUA), baseada nos ideais

\footnotetext{
${ }^{1}$ NKRUMAH, K. Africa Must Unite. Nova York: 1963.
} 
pan-africanistas. A OUA tinha como objetivo criar um espaço de diálogo, promover o desenvolvimento, combater o racismo e resolver pacificamente os conflitos internos do pós-independência ${ }^{2}$. No presente, uma expressão desse ideal é a União Africana (UA), que substituiu a OUA em 2002, e sua “Agenda 2063, a África que queremos", na qual a unificação política do continente é um dos objetivos a ser perseguido para a aceleração do desenvolvimento social e econômico.

Desde o início, o ideal de unificação recebeu várias críticas, principalmente dos próprios países africanos que, em sua maioria, optaram por uma alternativa lenta e gradual, sendo responsáveis pela trajetória ineficiente da OUA. Além disso, o caráter socialista do movimento, sobretudo no período da Guerra Fria, alimentou às críticas dos que se opunham a essa visão de mundo. Dentro do próprio movimento havia fissuras, como a causada por George Padmore, que abdicou dos ideais de inspiração socialista por uma visão estritamente nacionalista.

A continuidade dos ideais do Pan-africanismo nas alternativas para solucionar os problemas estruturais africanos na atualidade será o guia deste artigo. Será feita uma tentativa de compreender suas origens além das motivações que levaram os primeiros pensadores pan-africanistas a propor tal solução. Dividido em três partes, o presente artigo trará no primeiro tópico um breve histórico do movimento. No segundo momento será realizada uma análise da implantação de modelos político-econômicos alternativos que buscavam fugir da dicotomia LestelOeste que dominava o cenário político internacional na segunda metade do século XX e uma introdução a alguns críticos do Pan-africanismo. A última parte será dedicada à observação da continuidade do ideal Pan-africano no ideário político africano no presente como a Agenda 2063. Outras tentativas de integração - não necessariamente ligadas ao Pan-africanismo - também serão apresentadas ao longo do texto e será feito um balanço de seu nível de sucesso.

\section{ORIGENS DO PAN-AFRICANISMO}

\footnotetext{
${ }^{2}$ A OUA ficou conhecida pela sua ineficiência em relação tanto aos projetos de desenvolvimento econômico e de integração, quanto pela conivência às atitudes dos diversos ditadores que participavam ativamente da entidade sem sofrerem sanções, levando-a a receber a alcunha pejorativa de "clube dos ditadores". 50 ANOS DE UNIÃO AFRICANA. Disponível em: $<$ https://m.dw.com/pt-002/50-anos-de-uni\%C3\%A3o-africana/g-16825352>. Acesso em 20 jul.2019.
} 
As independências africanas são marcadas pelo otimismo que permeava os discursos de seus líderes. A libertação do jugo dos colonizadores europeus deveria promover o total desenvolvimento do Continente, acabaria com a pobreza e alçaria a África ao lugar de destaque no panorama das Relações Internacionais. O pensamento Pan-africano, baseado em intelectuais como W.E.B. DuBois e Kwame Nkrumah teria muita influência nesse momento-chave para o continente.

\section{Trajetória histórica e definições}

A construção da trajetória histórica do conceito de Pan-africanismo depende de uma definição do que pode ser considerado como parte desse movimento. Existe um consenso em apontar os congressos iniciados no século XX, realizadas em cidades como Manchester e Paris como marco histórico inicial do movimento. Posteriormente seriam organizados na África, em Acra e em Adis Abeba, outras edições dos congressos. Apesar disso, alguns autores, como o historiador e professor norte-americano John Henrik Clarke, consideram o surgimento do Pan-africanismo já no século XV, com o início do tráfico de africanos escravizados para a América. Essa visão considera o Pan-africanismo como uma forma de resistência, dessa forma, o deslocamento forçado para a América foi o primeiro momento em que os africanos tiveram a necessidade de se definir como tal para resistir e lutar contra os colonos europeus, antes disso o conceito de africano seria irrelevante prevalecendo a identidade regional (CLARKE, 1973, apud NANTAMBU, 1998, p. 565). O professor trinidadiano Kwame Nantambu vai ainda mais longe no tempo para buscar as fundações do Pan-africanismo. Para ele o surgimento desse conceito pode ser traçado até a união do Baixo e Alto Egito em 3220 a.C.. Essa teria sido a primeira ocasião em que povos africanos sentiram a necessidade de recorrer à união para resistir a um inimigo exterior (NANTAMBU, 1998, p.568). O autor propõe uma classificação do movimento Pan-africano em quatro períodos:

a) o $1^{\circ}$ período teria seu início com a unificação do Egito em 3200 a.C., sendo caracterizado pela resistência e luta contra invasores e a construção da nação; 
b) no $2^{\circ}$ período haveria a continuação da resistência contra invasores no Egito concomitante com o desenvolvimento sócio-cultural-político sob o general berbere Țāriq ibn Ziyād na conquista Islâmica da península Ibérica;

c) o $3^{\circ}$ período seria o do Nacionalismo Pan-Africano revolucionário, iria do século XV ao século XIX, sendo caracterizado pela resistência e luta dos africanos escravizados na África e na América;

d) por fim, o $4^{\circ}$ período seria caracterizado pelo Nacionalismo Pan-Africano intelectual, geopolítico, científico e cultural do século XX. Nesse período foram realizados os congressos Pan-africanos.

Nantambu considera outras abordagens, que ignoram o passado pré-colonial, como equivocadas e eurocêntricas, sugerindo inclusive uma nova terminologia, "Nacionalismo Pan-Africano", que seria mais apropriado (afrocêntrico) para descrever o conceito tradicionalmente referido como Pan-africanismo que seria definido como

(...) a luta/resistência nacionalista e unificada do povo Africano contra toda forma de agressão e invasão estrangeiras, na luta pela nacionalidade/ construção da nação ${ }^{3}$ .(NANTAMBU, 1998, p.569)

O Pan-africanismo não deve, portanto, se referir exclusivamente aos Congressos iniciados em 1900, mas como uma forma de luta e união dos povos africanos, independente de quando se encontram seus primórdios. Tendo isso em mente, para a produção deste artigo será considerado o quarto período do Pan-africanismo, que para Nantambu seria definido “pelo Nacionalismo Pan-africano intelectual, geopolítico, científico e cultural do século 20”, tendo como lideranças W.E.B. DuBois, Kwame Nkrumah, Frantz Fanon, James Baldwin entre outros. Será dada uma maior ênfase ao caráter geopolítico, que além de Nkrumah, Marcus Garvey e George Padmore, tem como representantes, entre outros, Maurice Bishop, Jomo Kenyatta, Walter Rodney, Steve Biko, Malcolm X e Peter Millard (autores que não serão abordados neste trabalho). Essa periodização se estende de 1900, com a conferência inaugural do Pan-africanismo em Londres até o presente.

\footnotetext{
${ }^{3}$ No original: "Pan-African Nationalism is the nationalistic, unified struggle/resistance of African against all forms of foreign aggression and invasion, in fight for nationhood/ nation building".
} 
No período anterior às conferências, o Pan-africanismo passou por um processo de gestação intelectual na diáspora. Homens como Blyden, Crummell, Garvey e DuBois ajudaram a construir o Pan-africanismo intelectual, vertente estreitamente ligada às independências.

O início do movimento é concentrado na diáspora, sobretudo EUA, Caribe e Grã-Bretanha e limitado ao círculo intelectual. A penetração das ideias na África viria apenas no pós Segunda Guerra Mundial. O caribenho Edward Blyden (1832-1912), considerado "pai do nacionalismo na África Ocidental", seria um dos pioneiros com um forte discurso focado no conceito de raça e na origem comum na África, que tornaria todos os negros do mundo membros de uma extensa irmandade. A raça, portanto, seria para ele um fator identitário. Um ponto pertinente abordado por Blyden, seria o de que a África, por ser formada por um único povo, incluindo os indivíduos diaspóricos, possuiria uma unidade natural. Dessa forma, do destino em comum dos negros, formado pelo tráfico negreiro e do isolamento do continente, derivaria a necessidade de unidade. Na sua visão o progresso viria com o fim do tráfico e o estabelecimento de relações com à Europa. Blyden introduz o conceito de pátria para os negros na África, cujo requisito para a cidadania seria ser negro (HERNANDEZ, 2008, p. 141-143).

O culto ao passado africano viria com Alexander Crummell (1819-1898), acompanhado de um forte elemento religioso. Civilizações como o antigo Egito, Etiópia e Núbia eram exaltadas, e a atividade missionária era vista como uma alternativa de desenvolvimento para o continente. Tendo dedicado a maior parte de sua vida a converter ao cristianismo africanos na Libéria e a incentivar outros afro-americanos a fazer o mesmo, não obteve muito sucesso. Blyden divergia fortemente de Crummell nesse aspecto, já que para ele, o cristianismo na África seria resultado de uma imposição cultural, enquanto o islamismo se daria por meio da persuasão. Assim o cristianismo seria um fator de fissura na sociedade, e o Islã um fator de unificação, o que teria enorme influência no movimento negro, principalmente nos EUA (HERNANDEZ, 2008, p.140-141). Esses diálogos representam algo como a ante-sala do Pan-africanismo.

Com W.E.B. DuBois, 1868-1963 há a criação das bases intelectuais e práticas do movimento. Pensando na construção do conceito de raça, DuBois conclui que os fatores sócio-históricos são mais relevantes do que os biológicos. Assim, é negada a ideia de 
superioridade uma raça sobre a outra, elas seriam complementares. Em DuBois há o início do processo intelectual que propunha a união da raça negra (HERNANDEZ, 2008, p. 143-144).

A ideia de unir todos os negros em único “organismo" é materializada por Marcus Garvey (1887-1940). Por meio da criação da UNIA (Universal Negro Improvement Association and African Communities League) em 1914 na Jamaica, ele irá promover a migração de centenas de afrodescendentes e africanos lançados na diáspora para a Libéria, que seria a nação central para os negros. Seu desejo era estabelecer na África uma alta cultura negra, onde haveria orgulho à raça, promoção dos heróis negros e ajuda às "tribos atrasadas da África". Seu modelo político-administrativo era baseado nos EUA. Apesar disso, suas atividades na África não previam um rompimento com o Império Britânico. Apenas posteriormente, Garvey passa a defender o ideal de independência. Seu projeto de migração fracassa, mas gera um movimento baseado nos EUA responsável por espalhar seus ideais pelo mundo (HERNANDEZ, 2008, p. 144-147).

\section{Os congressos Pan-africanos}

Considerando então o quarto período do Pan-africanismo, seu ponto de partida é a Conferência de Londres, organizada por Henry Sylvester-Williams (1869-1911), realizada em 1900. Contando com a presença de aproximadamente 40 delegados de países como Libéria, Gana, Cuba, Antigua, Serra Leoa, Costa do Marfim e Jamaica, entre outros, além da presença de vários estadunidenses e britânicos ligados à causa da população de africana e afrodescendente a Conferência trazia em seu convite a seguinte mensagem

Essa conferência é organizada pela Associação Africana para a discussão da questão das "Raças Nativas", e vai ser atendida e endereçada por aqueles de ascendência africana de todas as partes do Império Britânico, Estados Unidos da América, Abissínia, Libéria, Haiti, etc.

A conferência possuía como objetivos principais as seguintes ações (SHERWOOD, 2012, p. 107):

\footnotetext{
${ }^{4}$ No original: "This conference is organized by a Committee of the African Association for the Discussion of the "Native Races" Question, and will be attended and addressed by those of African descent from all parts of the british Empire, the United States of America, Abyssinia, Liberia, Hayti, etc".Disponível em: < https://www.wikiwand.com/en/First_Pan-African_Conference>. Acesso em 20 jun.2019.
} 
- Assegurar os direitos civis e políticos para os africanos e seus descendentes em todo o mundo;

- Incentivar relações amistosas entre as raças caucasiana e africana;

- Encorajar os africanos em toda parte em empreendimentos educacionais, industriais e comerciais;

- Abordar os governos e influenciar a legislação no interesse das raças negras; e para melhorar a condição do negro oprimido em todas as partes do mundo.

Baseado nos trabalhos apresentados, fica claro que na primeira Conferência Pan-africana as preocupações eram mais voltadas às questões das políticas raciais do que para as independências das colônias africanas. Os participantes apresentaram trabalhos como "Conditions Favouring a High Standard of African Humanity” (C. W. French de São Cristovão); “The Preservation of Racial Equality” (Anna H. Jones, dos Estados Unidos); "The Necessary Concord to be Established between Native Races and European Colonists" (Benito Sylvain, adido de campo do imperador etíope); "The Negro Problem in America" (Anna J. Cooper, dos Estados Unidos); "The Progress of our People" (John E. Quinlan de Santa Lúcia) e "Africa, the Sphinx of History, in the Light of Unsolved Problems" (D. E. Tobias dos Estados Unidos). A maior parte dos participantes eram afro-americanos, portanto é compreensível que suas preocupações estivessem mais voltadas para as condições dos negros na América. Não obstante, foram debatidos assuntos diretamente referentes ao continente africano, sendo notável uma preocupação com a política segregacionista sul-africana, que décadas depois iria desembocar no apartheid.

Mesmo que não tenha tido resultados concretos duradouros, a primeira Conferência foi importante para os ainda incipientes movimentos emancipatórios que levariam à independência das colônias africanas, 60 depois. Ela demonstrou para a população não negra, graças à imprensa que cobriu amplamente a Conferência, e para os governantes coloniais, a capacidade dos negros de se reunirem para discutir seu futuro. Além disso, a Conferência daria início à série de congressos Pan-africanos, culminando com o Congresso Pan-africano de 1945 . 
Considerado o mais importante dos congressos Pan-africanos, o Congresso de 1945, realizado em Manchester, Inglaterra, seria fortemente político e dominado pelo contexto do pós-Guerra. Seriam assinadas várias resoluções que teriam consequências diretas nos movimentos de independência africanos (SHERWOOD, 2012, p.108-109). Futuros líderes africanos como Hastings Banda, Jomo Kenyatta e Kwame Nkrumah, participaram ativamente do congresso, além de figuras notórias ligadas ao movimento negro como o organizador do congresso George Padmore, W.E.B. DuBois e Joe Appiah. As demandas eram o fim do domínio colonial e o fim da discriminação racial, além de promover à luta contra o imperialismo, pelos direitos humanos e pela igualdade de oportunidades econômicas.

Os ideais defendidos no Congresso de 1945 estão intimamente ligados ao pensamento de Nkrumah, que influenciaria não apenas a independência e o futuro de seu país, mas de grande parte do continente africano.

\section{O pensamento Pan-africano de Nkrumah}

Em seu livro Africa Must Unite, o líder ganense Kwame Nkrumah detalha de maneira pormenorizada todos os fatores que tornariam a união política de todos os países africanos a melhor, e talvez única, opção para que a África consolidasse sua independência e alcançasse seu total desenvolvimento. São listados no livro tanto os fatores positivos para a unificação, com um enfoque nos enormes volumes de riqueza natural do continente, como os negativos, como a baixa quantidade de profissionais treinados. A união do continente seria a solução para os problemas e também à forma de se desenvolver por completo o potencial econômico e humano africano. Num tom extremamente otimista, apesar de levar em conta vários perigos externos provocados principalmente pelas disputas geopolíticas da Guerra Fria e pelo interesse que as ex-potências coloniais teriam no continente, o autor escreve na prática uma espécie de manual para o sucesso africano (NKRUMAH, 1963).

Kwame Nkrumah considerava que a independência de Gana em 1957, conduzida pelo Convention People's Party (CPP), seria o estopim para a libertação generalizada das demais colônias africanas. Na sua visão, a luta pela independência deveria ser supranacional, sendo uma obrigação do partido e do novo Estado por ele governado apoiar os demais movimentos 
nacionalistas; essa seria a maneira de se alcançar o propósito final da unificação política de todo o continente africano. Os antecedentes da colonização e o imperialismo da Guerra Fria trariam perigos para as recém-conquistadas liberdades, sendo a unificação a melhor e talvez única forma de garanti-la. Como agravante, Nkrumah elenca vários fatores como à baixa produtividade agrícola, a dependência de estrangeiros no comércio, o baixo nível de alfabetização, a infraestrutura precária, dependência internacional de bens cotidianos. Todos esses fatores contribuiriam para tornar a independência mais frágil (NKRUMAH, 1963, p. 9-20).

É bastante evidente que para Nkrumah a independência de Gana significava bem mais do que apenas a liberdade dos ganenses. O país deveria servir como exemplo para todo o continente, demonstrando a capacidade dos africanos de se autogovernarem. Várias iniciativas foram criadas visando atrair povos de outros países africanos, independentes ou não, para receberem treinamento burocrático e administrativo. Isso evidencia que para Nkrumah, o ideal Pan-africano estava em um plano bem mais relevante do que o nacional, o que ficaria claro com os constantes conflitos internos com diversos grupos de Gana que buscavam maior autonomia em relação ao governo central ou ao menos uma relação mais transparente com o primeiro-ministro e o partido. Esses conflitos levariam Nkrumah a declarar Gana como um Estado de partido único e estabelecer um governo centralizador, de aspecto ditatorial (BINEY, 2011, p. 65-66).

Ao mesmo tempo em que considerava que as medidas tomadas foram necessárias para a consolidação da independência, Nkrumah acusava a imprensa internacional de não cooperar com o novo país ao apoiar medidas que poderiam fragmentá-lo. Dessa forma, o controle sobre os partidos e o cerceamento da liberdade de imprensa seriam justificáveis para se alcançar o bem maior, que seria à consolidação da independência e a pavimentação do caminho para a união Pan-africana.

\section{Socialismo africano}

Em um interesse artigo publicado na Revista Brasileira de Ciências Sociais, o sociólogo Fabrício Cardoso de Mello explora a inspiração socialista em movimentos que buscavam emancipação contra regimes coloniais. Ele constrói seu argumento a partir das trajetórias políticas de José Carlos Mariátegui, no Peru, Léopold Sédar Senghor, no Senegal e 
Kwame Nkrumah, em Gana. Esses três autores propuseram adaptações do socialismo às realidades da África e da América Latina, enxergando o socialismo como uma via política para a construção de novas sociedades que superassem o colonialismo (MELLO, 2016).

Por meio da comparação entre os três autores, Mello identifica três pontos em comum em sua forma de elaboração de estratégias de resistência: a) ressignificação do socialismo a partir de contextos sociais não industriais; b) incorporação de elementos societários pré-coloniais como fatores necessários a um futuro emancipatório; c) diferentes alternativas de integração regional que servissem de eixo comunitário no contexto pós-colonial (MELLO, 2016, p. 3-6).

O contexto encontrado na África por Senghor e Nkrumah, na década de 1940, era a colonização do continente por potências europeias, portanto, seu primeiro objetivo deveria ser a independência. Para Nkrumah, o socialismo era um instrumento para alcançar um objetivo que ia além das independências individuais das colônias africanas, levando a união Pan-africana. Para o sucesso desse objetivo, se fazia necessário um partido de massas, que se concretizou com a fundação do Convention People’s Party em 1949. Na visão de Nkrumah, o partido teria o papel de lutar contra as elites locais que serviam de intermediários entre a administração colonial e as massas. Representando os interesses de toda a nação, o CPP seria o líder natural da implantação do socialismo. Mais do que ser apenas contra o colonialismo, ele era contrário a ideia de libertação gradual, defendendo o corte imediato dos laços políticos com a metrópole. Isso permitiu uma generalização extrema de seu discurso, dando uma ênfase ao nacionalismo com a intenção de formar uma identidade nacional homogênea em oposição à dominação imperialista (MELLO, 2016, p. 3).

$\mathrm{Na}$ concepção tanto de Senghor quanto de Nkrumah, haveriam elementos inerentes aos africanos que tornariam a implantação do socialismo mais tranquila do que pregava a teoria marxista. Assim não haveria uma revolução liderada por uma vanguarda, no estilo bolchevique, mas sim uma "reapresentação" dos princípios comunitários africanos pelo partido. Esses princípios, que podem ser reunidos sob o conceito de comunalismo, fariam com que não houvessem estranhamentos da população africana com o comunismo e o socialismo. Mas o socialismo só poderia ser implantado após a conquista da independência política (MELLO, 2016, p. 5).

Nkrumah muda de perspectiva com o avançar das independências. Perde o saudosismo das antigas civilizações africanas, que seria característico da Negritude, e repensa 
o conceito de conflito de classe, o qual anteriormente ele considerava que não existia em África. A luta de classes na África seria o fruto das alianças das metrópoles com as diferentes elites locais. Também desaparece o fator voluntário para a implantação do socialismo, sendo necessária uma ação mais efetiva do partido e dos líderes (MELLO, 2016, p. 9-10).

Um fator que oporia as trajetórias de Senghor e Nkrumah seriam os resultados que seus movimentos nacionais teriam. Enquanto o ganense propunha o fim imediato das relações de dependência com os ingleses, o senegalês, assim como outros chefes de Estado das ex-colônias francesas, optou por manter o país em uma aliança supranacional, que teria a França como líder. A liderança e a capacidade de investimentos franceses eram bastante atraentes para países como o Senegal e a Costa do Marfim, tanto que até hoje a França é responsável pela política monetária de algumas de suas ex-colônias, algo impensável para Nkrumah.

A impossibilidade de reprodução do socialismo europeu na África impôs a necessidade de soluções originais como as propostas por Senghor e Nkrumah. Ambos partem de uma valorização do fator africano, embora de forma distintas. Enquanto Senghor baseia seu discurso num elemento como o "ritmo", que seria a valorização da subjetividade africana em oposição à objetividade da filosofia greco-romana, Nkrumah valoriza à ausência de classes, que promoveria uma horizontalidade nas relações, facilitando a introdução do socialismo no continente (MELLO, 2016, p.5).

Senghor, seria um dos idealizadores do conceito de Negritude e com a independência do Senegal se tornaria presidente de seu país em 1960, sendo reeleito diversas vezes até 1980. Apesar do tom crítico em relação à forma como o Ocidente, principalmente a França, se relacionava com a África, manteria relações próximas sendo eleito para a Académie Française, vindo a falecer em 2001 na Normandia. Garantiria com isso um legado de estabilidade ao seu país além de eleger um sucessor. Sempre guiado pelo ideal Pan-africano, instrumentalizado por meio do socialismo, Nkrumah teria todas as suas decisões pautadas nesses ideais, o que condicionará fortemente sua resposta às diversas crises por qual passaria seu país e o continente no momento das independências. A abordagem de Nkrumah vai sendo modificada com o decorrer dos anos, tentando sempre se adaptar às novas realidades. Mas o destino político de Nkrumah acabou por ser bastante conturbado - de líder inconteste da campanha pela independência, para primeiro-ministro, depois presidente vitalício por meio de uma emenda aprovada por uma eleição claramente fraudulenta, e por fim exilado devido a um 
golpe organizado por seus rivais. Isso promoveria uma imagem bastante negativa do movimento, sendo possivelmente um dos fatores responsáveis pelo sucesso de uma visão mais conservadora para o continente na construção das alternativas de desenvolvimento, sendo a OUA e sua trajetória um exemplo disso.

\section{ALTERNATIVAS E CRÍTICAS AO PAN-AFRICANISMO}

Países que, no momento de suas independências, buscaram adotar um modelo sócio-político original, como Gana e Guiné ou posteriormente, como o Burkina Faso, tiveram seus governos transformados em ditaduras, sofreram com golpes internos e interferências externas interditando as alternativas de desenvolvimento. Por outro lado, países colaboracionistas e alinhados com o Ocidente, como a Costa do Marfim ${ }^{5}$, experimentaram um nível de estabilidade considerável, mas com as reproduções das desigualdades estruturais do tempo colonial. As tentativas iniciais de cooperação a nível continental ou regional também não obtiveram sucesso no momento após a conquista das independências.

Durante o período das independências, ocorreram diversas baixas entre os que buscavam uma alternativa africana de desenvolvimento. A morte de Patrice Lumumba e a ascensão de Mobutu Sese Seko, na República do Congo ${ }^{6}$, já em 1961, é um forte exemplo disso. Em Gana, o governo de Nkrumah se torna autoritário e teria fim em 1966, com a tomada do poder pelos militares. O assassinato de Thomas Sankara, no Burkina Faso, em 1987, poria fim a uma das últimas experiências influenciadas pela mescla de elementos africanos e socialistas que foram pensados para a África como ferramentas de independência e desenvolvimento.

A trajetória da implantação do modelo democrático ocidental na África foi, no geral ineficiente. A manutenção do modelo democrático em Botsuana e Ilhas Maurício, com garantias de direitos civis, liberdade de imprensa e multipartidarismo, são exceções num

\footnotetext{
${ }^{5} \mathrm{O}$ envolvimento de Houphouet-Boigny em vários golpes na África Ocidental, além de suas tentativas de conter os movimentos de independência, exemplifica o alinhamento de seu país com interesses de países da França principalmente.

${ }^{6}$ Atualmente República Democrática do Congo
} 
continente com 55 Estados $^{7}$. Além disso, o modelo socialista pretendido por Nkrumah e Sankara, fracassou. Para isso contribuiu o domínio do contexto da política internacional pelos conflitos político-ideológicos da Guerra Fria, que tiveram um peso considerável no futuro de diversos países africanos, logo num momento de fragilidade que representava a conquista de suas independências ${ }^{8}$.

\section{Críticas ao Pan-africanismo}

Em uma crítica aos modelos sociopolíticos africanos que foram pensados dentro do contexto da conquista das independências, o pensador camaronês Achille Mbembe tece importantes considerações sobre as duas principais correntes que surgiram no continente, o Pan-africanismo e Nègritude (MBEMBE, 2001). Para o autor, o Pan-africanismo se define como democrático, radical e progressista. Possui caráter marxista e nacionalista, trazendo em seu discurso uma manipulação dos discursos da autonomia, resistência e emancipação como critério para construir seu argumento como legitimamente africano. Com o desejo de falar por todo o continente, o Pan-africanismo, assim como a Nègritude, considera três momentos chaves responsáveis pela situação experienciada pelos africanos a partir do século XV: a escravidão, o colonialismo e o apartheid. Esses eventos resultaram na expropriação material e na sujeição dos africanos, por meio da falsificação da história africana pelos europeus. Esses fatores seriam responsáveis pela "tragédia" da história africana. Essas duas correntes teórico-políticas defendem que esses fatores são responsáveis pelo desejo africano de autonomia e autoconhecimento.

A crítica de Mbembe se direciona ao fato de que nenhuma das correntes buscou pensar de maneira aprofundada e filosófica a problemática representada pelos três momentos que reconhecem como chave da história africana. Eles são puramente aceitos e a partir daí são criadas as supostas teorias originais africanas, sem que sejam feitas as devidas problematizações, inclusive sobre a participação africana no colonialismo e no tráfico de escravos. Essa visão acrítica da História cria uma espécie de "vitimismo" entre os africanos,

\footnotetext{
${ }^{7}$ Deve-se levar em consideração o fato de que resolução dos problemas africanos referente à estabilidade do Estado demanda tempo. A Europa, por exemplo, demorou séculos para consolidar seus regimes e a América Latina ainda não solucionou essas questões. (ANGLARILL, 1997, p.1-7)

${ }^{8}$ Exemplos diretos das dinâmicas da Guerra Fria podem ser encontrados tanto no Congo como nas ex-colônias portuguesas (SCHMIDT, 2013, p.79-101).
} 
que não se consideram responsáveis pelos acontecimentos do seu passado, colocando a culpa sempre no Outro. O Pan-africanismo se alimentaria disso, colocando a luta revolucionária acima de tudo, com ênfase na violência, desrespeito pela democracia e elogio ao autoritarismo populista (MBEMBE, 2001, p. 174-177), características presentes em Gana durante o governo Nkrumah. Aqui é possível fazer um resgate à crítica proposta por Kwame Nantambu de renomear o Pan-africanismo como Nacionalismo Pan-africano, pensando a história do continente além das consequências do contato com os europeus no século XV e do colonialismo posterior, iniciando a trajetória histórica do movimento a partir da união do Baixo e do Alto Egito (NANTAMBU, 1998).

Mbembe (2001, p. 175-176) identifica quatro principais características do Pan-africanismo:

- $1^{\circ}$ : conhecimento e ciência não são independentes, estão ao serviço da luta partidária revolucionária;

- $\quad 2^{\circ}$ : visão mecânica e reificada da História. Ela seria dominada por um conjunto de forças invisíveis e reduzida a um conjunto de fenômenos de sujeição, determinista;

- $\quad 3^{\circ}$ : destruição da tradição e elogio ao proletariado urbano e rural. Reduzir o papel revolucionário ao proletariado é problemático devido ao fato de negar os demais grupos sociais;

- 4: culto à vitimização. São conferidas características "pseudo-históricas" ao continente africano, que está submetido a um "nome racial”, assim, os indivíduos que possuem determinadas características podem se identificar

Mbembe também considera que as duas teorias sobrevalorizam o conceito de raça. Raça seria considerada o principal fundamento da formação do self e da ideia de nação e serviria como base para a solidariedade política. Haveria algo como uma equivalência entre raça e geografia, de onde se deriva a identidade cultural africana. Dessa forma, o negro adquire sua cidadania por causa de sua cor e de onde mora, não por causa de direitos políticos inerentes à humanidade (MBEMBE, 2001, p. 182-185).

Fica claro na argumentação de Mbembe que o intelectual camaronês não considera o Pan-africanismo uma solução ideal para a África, principalmente se forem usados os exemplos históricos de tentativa de implantação deste modelo. No entanto, sua discordância é ainda maior, também ancorando-se em uma sistemática crítica da teoria. A partir dessa 
crítica, podem ser feitas leituras tanto sobre as tentativas de integração que compartilham alguns pontos com os pan-africanistas, como pensar nas futuras tentativas de desenvolvimento socioeconômico no continente.

Outra crítica ao Pan-africanismo é encontrada em um artigo publicado em 1988, do jornalista sul-africano Paul Trewhela, que constrói um contundente argumento crítico à obra de um dos principais teóricos Pan-africanos, George Padmore, posteriormente extrapolado para o movimento em geral. Trewhela usa como fonte principal de sua crítica, o livro publicado por Padmore em 1956, Pan-Africanism or Communism? The Coming Struggle for Africa, considerada a principal obra do autor, que têm como premissas o anti-stalinismo, o nacionalismo e a unidade Pan-africana (TREWHELA, 1988).

Nascido em Trinidad em 1903, Padmore foi membro do Partido Comunista dos EUA, deputado do Soviete de Moscou e oficial da Terceira Internacional. Apesar disso, irá romper com Moscou devido à aproximação da União Soviética com as potências coloniais no contexto da ascensão do nazismo e da Segunda Guerra Mundial. Ele abandona os ideais marxistas a favor de uma perspectiva estritamente nacionalista, embora ainda deseje um governo socialista para os futuros Estados Unidos da África, mas que seria alcançado sem a necessidade de uma revolução proletária no molde bolchevique. Desalentado com a posição adotada por Stalin na Segunda Guerra Mundial, alinhamento com a Grã-Bretanha e a França, além do desincentivo aos movimentos revolucionários nas colônias africanas, Padmore passa a crer que os africanos só poderiam contar consigo mesmos para obter a independência (TREWHELA, 1988, p.42-43).

Trewhela critica fortemente a aparente dualidade do pensamento de Padmore em relação à União Soviética. Ele não parece se importar muito com as medidas internas de Stalin, como a perseguição implacável a inimigos políticos ou o uso de trabalho forçado nos grandes projetos realizados na União Soviética. Mesmo vivendo em Moscou nesta época, não há comentários em seu livro sobre as graves consequências sociais e humanitárias do stalinismo. Outro fator é o seu posicionamento em relação aos movimentos independentistas e/ou socialistas na Ásia, sendo abertamente favorável ao governo de Ho Chi Minh, que persegue trotskistas, entre outros dissidentes e opositores, estando, portanto, alinhado aos interesses stalinistas. Assim, para o autor, a sua posterior crítica e rompimento seriam superficiais. Segundo Trewhela, Padmore se incomoda com as consequências do stalinismo em relação à África, mas ignora as consequências na China ou no Vietnã, por exemplo. Fecha 
os olhos para a perseguição de minorias na União Soviética alegando se tratar de assuntos internos, logo não diziam respeito aos negros. Portanto, Padmore teria realizado uma divisão entre a política externa e interna da URSS, entre os assuntos que dizem respeito à opressão imperialista no continente africano e aos relacionados à mesma opressão imperialista na Ásia (TREWHELA, 1988).

Mesmo em relação às independências, a posição de Padmore teria sido ambígua. Ele escreve $^{9}$ que o ideal seria a Grã-Bretanha conceder a independência de forma pacífica, e assim continuar a manter o controle indireto sobre as colônias por meio da Commonwealth, uma atitude difícil de conciliar com os ideais pan-africanistas. Nkrumah, por exemplo, pregava o corte imediato de qualquer relação com as potências coloniais (NKRUMAH, 1963, p.50-56). Padmore faz um elogio às burguesias e intelligentsia locais, tanto na África como na Ásia. Assim o papel popular é menosprezado, já que apenas líderes fortes seriam capazes de manter a população "na coleira” (PADMORE, 1942, p.47). A população apenas trocaria de senhor: antes os europeus e agora os líderes revolucionários nacionais. Não há no programa independentista Pan-africano, ao menos na visão de Padmore, uma preocupação com uma verdadeira e total libertação popular. Isso é algo que irrita profundamente Trewhela, que sintetiza os movimentos de independência em uma frase:

Esse é o ponto central do programa: as pessoas devem ser mantidas na coleira. ${ }^{10}$

(TREWHELA, 1988, p.57).

Outro ponto extremamente controverso analisado por Trewhela na obra de George Padmore, é a crítica feita à burguesia indiana enriquecida na África do Sul. Segundo o autor, Padmore buscava criar um bode expiatório, tal como os judeus foram usados na Alemanha nazista, sendo diretamente responsável pela teoria que alimentaria atrocidades como a expulsão de asiáticos, realizada pelo governo de Idi Amin em 1972 em Uganda (TREWHELA, 1988, p. 58).

A análise de Trewhela s sobre a visão de George Padmore é muito útil para uma visão crítica do Pan-africanismo, já que grande parte dos demais autores Pan-africanistas ao citá-lo,

\footnotetext{
${ }^{9}$ CUNARD \& PADMORE. The white man's duty: an analysis of the colonial question in the light of the Atlantic Charter. 1942

${ }^{10}$ No original: "That is the heart of the programme: the people are to be kept in leash".
} 
possuem um tom celebratório e saudosista ${ }^{11}$. Seus posicionamentos parecem variar largamente de acordo com o contexto, não havendo fidelidade nem aos ideais Pan-africanos e menos ainda aos ideais marxistas, adotando um tom bastante próximo ao stalinismo. Os ideais teóricos Pan-africanos entram em questão, sobretudo ao se observar o resultado das aplicações desses ideais no continente. Deve-se levar em conta que Trewhela ao escrever sua crítica estava exilado em Londres devido ao seu envolvimento com o Partido Comunista Sul-Africano e à luta contra o apartheid. Nesse momento chave para o país, os ideais do Pan-africanismo apareciam como importantes referenciais para o futuro da África do Sul. Trewhela claramente preferia a implantação do "verdadeiro marxismo". Ele conclui que

O Pan-africanismo se revela como mais uma escola de intermediação entre capital e trabalho, impedindo o proletariado de tomar seu destino e o destino da humanidade em suas próprias mãos ${ }^{12}$. (TREWHELA, 1988, p. 61)

O surgimento de líderes populistas e autoritários na África a partir das conquistas das independências é bastante sintomático quando se analisa a obra de um dos principais teóricos do movimento que daria início aos processos de independência em vários países africanos. Os fins justificariam os meios, portanto, governos autoritários e de exceção são aceitos desde que levem a independência a cabo, sem levar em conta os custos que a população tem que pagar ${ }^{13}$. Não obstante, seria muito simplista culpar os idealizadores do Pan-africanismo pelas ações dos vários líderes revolucionários que usaram seus ideais para legitimar suas ações. Uma leitura crítica dos princípios do movimento é indispensável, principalmente quando soluções para o continente são pensadas baseadas nesses princípios.

Um dos líderes autoritários e populistas que ascendeu ao poder durante o processo de independência é Felix Houphouet-Boigny, líder da independência da Costa do Marfim e presidente do país por 30 anos. Houphouët-Boigny dificilmente pode ser classificado como pan-africanista, apesar disso, a união política africana pretendida pela Agenda 2063 vai se concretizar da maneira como foi idealizada e defendida por ele: unificação de forma lenta e gradual. Durante seu governo, seu país experimentaria níveis de desenvolvimento e

\footnotetext{
${ }^{11}$ Nkrumah dedica seu livro Africa Must Unite a Padmore; C.L.R. James faz vários elogios ao citar o "pai da emancipação africana" (JAMES, 1980, p.227).

${ }^{12}$ Original: Pan Africanism reveals itself as yet another school of intermediation between capital and labour, obstructing the proletariat from taking its destiny, and the fate of humanity, into its own hands.

${ }^{13} \mathrm{O}$ slogan cunhado por Nkrumah utilizado na campanha de independência de Gana, "Seek ye first the political kingdom and all things shall be added unto you", é bastante ilustrativo do quão importante era a independência para os pan-africanistas. (NKRUMAH, 1957).
} 
estabilidade econômica acima da média africana ${ }^{14}$. No aspecto político, se envolveria em tentativas de sufocamento de movimentos de inspiração socialista como o de Nkrumah em Gana, Mathieu Kérékou no Benin e Thomas Sankara no Burkina Faso, além de manter seu país como o principal colaborador da política francesa na África Ocidental.

Em um discurso na ONU, em 1957, Houphouët-Boigny advoga pela criação de uma comunidade Franco-Africana em detrimento da independência total e radical, fazendo oposição ao que propunha Nkrumah e os demais pan-africanistas. Ele argumentava que devido ao mundo estar cada vez mais conectado e interdependente, o ideal de independência não seria tão relevante assim. Citando algumas organizações europeias, onde as nações abrem mão de parte de sua soberania para participar, Félix Houphouët-Boigny busca validar seu raciocínio (HOUPHOUËT-BOIGNY, 1957, p. 593-599). Sua decisão de ir contra a tendência generalizada de independência o isola do restante dos líderes revolucionários. Apesar disso, sua popularidade interna somada à prosperidade experienciada pela Costa do Marfim o deixa extremamente confiante no seu posicionamento. Apenas quando a independência se torna inevitável, devido a fatos como o reconhecimento das independências dos vizinhos por parte de Paris, a criação da união Gana-Guiné e da Federação do Mali além de conflitos internos, tem fim seu ideal republicano federativo. Assim, sem ter outras opções, Houphouët-Boigny é praticamente obrigado a declarar a independência da Costa do Marfim (CARTER, 1964).

Posteriormente à independência, durante as discussões e conferências em que se debatiam o futuro do continente, Houphouët-Boigny, junto a outros gradualistas como Nnamdi Azikiwe, da Nigéria, Jomo Kenyatta, do Kenya e Julius Nyerere, da Tanzânia, irá propor uma unificação lenta e gradual, radicalmente oposta ao pensamento Pan-africano de Nkrumah, Ahmed Ben Bella, da Argélia, Patrice Lumumba, do Congo, Ahmed Sekou Touré, da Guiné e Modibo Keita, do Mali (MARTIN, 2012, p.55-71). Essa forma gradual será a escolhida, se materializando na criação da OUA em 1963, que iniciaria um lento e infrutífero processo de integração (RODRIGUES; CAPUTO, 2013, p.108), que se arrastaria por décadas, sendo acelerado com a substituição da OUA pela UA, e que só terá fim em 2063, o que parece ser uma proposta mais viável do que à união imediata dos 55 Estados africanos.

\footnotetext{
${ }^{14}$ As taxas de crescimento ficariam acima dos $6 \%$ por décadas, a agricultura se mantém como a principal setor, mas como uma diversificação da produção pouco vista na África. (MALDONADO, 2008) Não obstante, o modelo predatório adotado na Costa do Marfim teria consequências ambientais graves, se prolongando até o presente. Disponível em $<$ https://economia.uol.com.br/noticias/bloomberg/2016/10/17/costa-do-marfim-destroi-florestas-tropicais-por-ca cau.htm>. Acesso em 21 jun. 2019
} 
Se a imediata unificação poderia trazer consequências positivas e resolver os problemas africanos como pregavam os pan-africanistas, é algo que só pode ser especulado, mas é Nkrumah o citado nos documentos da Agenda 2063, e não Houphouët-Boigny.

\section{Propostas alternativas para o mapa da África}

Além das propostas de integração de Nkrumah e dos pan-africanistas, vários outros autores propuseram alternativas para o continente. Num livro publicado em 2012, Guy Martin faz uma análise de sete dessas alternativas, entres elas estão as criadas por Cheikh Anta Diop, Marc-Louis Ropivia, além do próprio Martin.

A primeira dessas alternativas é a proposta de Cheikh Anta Diop, o Estado Federal Africano (MARTIN, 2002, p. 275-276). Baseado em uma pesquisa que documenta e unidade histórica, cultural e linguística africana, propõe o uso de uma linguagem única no continente para questões educacionais, culturais e oficiais. Para defender à união política e econômica imediata dos Estados africanos, com a exceção do Norte da África, Diop alerta contra a "South Americanization" da África, que seria proliferação de pequenos Estados ditatoriais e instáveis. Propõe o fim das "falsas instituições", como a comunidade Franco-Africana e a Commonwealth. Além da exclusão dos países ao norte do Saara, outro ponto original da proposta de Diop é a criação de políticas de incentivo ao crescimento populacional, já que na sua visão o continente seria subpovoado.

Crítico das raízes norte-americanas do Pan-africanismo e com uma teoria que vai diretamente contra a proposta de Diop, Marc-Louis Ropivia nega que existe uma cultura geral no continente, valorizando a diversidade cultural que levaria a não uma, mas várias federações regionais. O novo federalismo africano proposto por Ropivia é baseado em unidades compostas por dois estados com o mesmo background colonial, chamadas "núcleos bi-estaduais" ou "díades federativas". Progressivamente seriam feitas reuniões com mais estados, até o ponto de se criar uma federação continental.

Martin, junto a Mueni wa Muiu, também propõe um novo Estado africano, que seria baseado em cinco unidades formadas a partir dos aspectos étnicos em comum. A Federação dos Estados Africanos (FAS na sigla em inglês), contaria com uma constituição e política de defesa exterior únicas. Haveria uma nova capital, chamada Napata, que funcionaria de forma autônoma em relação aos 5 super-Estados. Cada um dos super-Estados contaria com um 
key-player, que seriam por exemplo, Congo, Egito, Etiópia, Nigéria e África do Sul. Na estrutura da FAS haveria um elaborado esquema de descentralização, contado com várias instituições do nível da vila até o continental ${ }^{15}$.

Essas teorias e alternativas ajudam a compor um quadro em que à unificação política do continente é algo recorrente nas ideias de governantes e cientistas sociais. O Pan-africanismo e as propostas que se baseiam em seus princípios, portanto, não representam um ponto fora da curva, mas apenas uma forma de compreender e pensar o futuro africano inserido num contexto ideológico maior.

\section{PAN-AFRICANISMO CONTEMPORÂNEO}

Num discurso, na conferência da União Africana, em Acra, em 2007, o ministro das relações exteriores do Senegal, Cheikh Tidiane Gadio, declarou que: "Nós estamos prontos para abandonar parcialmente ou totalmente nossa soberania para nos juntarmos a um governo de unidade na África." ${ }^{, 16}$ Convocada por Muammar Gaddafi, a conferência tinha por objetivo discutir um projeto de integração política Pan-africana. A persistência de ideias Pan-africanas se mostra viva nos projetos e no imaginário dos policy makers africanos. Um exemplo vivo é a Agenda 2063, a qual traz, logo na sua segunda aspiração, que a "África será um continente integrado, unido, pacífico, soberano, independente, confiante e auto-suficiente" (AFRICAN UNION, 2013). Ao longo dessa última parte, tentaremos apresentar a continuidade dos ideais Pan-africanos e suas adaptações na contemporaneidade, a partir da análise de parte dos documentos que compõem a Agenda 2063.

\section{Tentativas de integração}

A parte a aversão de vários Estados à questão ideológica imbricada no Pan-africanismo, fatores econômicos tiveram um peso considerável no sucesso e insucesso dos projetos de cooperação e desenvolvimento realizados em África no pós-independência. A

\footnotetext{
${ }^{15}$ É importante notar que Martin logo na introdução de seu livro considera que à nova proposta de integração da UA, à Agenda 2063, está fadada ao fracasso (MARTIN, 2012, p.6).

${ }^{16}$ Original: We are ready to abandon partially or totally our sovereignty to join a unity government in Africa. Disponível em: $<$ https://www.globalpolicy.org/component/content/article/173/30539.html.> Acesso em 29. Jun. 2019
} 
crise por qual passava o continente nos anos posteriores às independências, além da forte ingerência de interesses externos no contexto da Guerra Fria, seriam forte obstáculos para as tentativas mais arrojadas com fortes fatores ideológicos como, o Pan-africanismo, sendo substituídas por outras menos ambiciosas e de caráter regional.

Por exemplo, o Tratado de Abuja, 1991, estabeleceu a Comunidade Econômica Africana. Assinado por 51 chefes de Estado africanos, lançou as bases para o projeto de integração continental. O tratado previa a criação de Comunidades Econômicas Regionais (CER) e o fortalecimento das já existentes, que serviriam como base para a Comunidade (AFRICAN UNION, 1991, p. 8). Por meio da integração em etapas, seria alcançado o objetivo que englobaria todos os países africanos. O Tratado de Abuja previa seis etapas de integração (RODRIGUES; CAPUTO, 2013, p. 114):

- $1^{\circ}$ (1994-1999): criação de blocos econômicos regionais onde não existem.

- $2^{\text {o }}$ (2000-2007): fortalecimento da integração nas comunidades regionais e harmonização entre essas comunidades.

- $\quad 3^{0}$ (2008-2017): estabelecimento da área de livre comércio e da união aduaneira em cada comunidade regional.

- $\quad 4^{\circ}$ (2018-2019): coordenação e harmonização dos sistemas tarifários e não tarifários entre as comunidades regionais visando ao estabelecimento da área de livre comércio e da união aduaneira africanas.

- $\quad 5^{\circ}$ (2020-2023): estabelecimento do mercado comum africano.

- $6^{\circ}$ (2024-2028): estabelecimento da união econômica e monetária africana e do parlamento africano.

Atualmente, existem no continente $13 \mathrm{CER}$, das quais 8 são reconhecidas pela União Africana como ponto de partida para o projeto maior de integração continental. ${ }^{17}$ A África Ocidental, África Oriental e a África Austral possuem bons exemplos de tentativas de

\footnotetext{
${ }^{17}$ As CER reconhecidas pela União Africana são: Comunidade Econômica do Sahel-Sahariano (CEN-SAD); Mercado Comum da África Austral e Oriental ( COMESA); Comunidade da África Oriental (EAC); Comunidade Econômica dos Estados da África Central (ECCAS); Comunidade Econômica dos Estados da África Ocidental (ECOWAS); Autoridade Intergovernamental de Desenvolvimento (IGAD), Comunidade de Desenvolvimento da África Austral (SADC) e União Árabe do Magrebe (UMA). As não reconhecidas são: União Aduaneira da África Austral (SACU); Comunidade Econômica dos Países dos Grandes Lagos (CEPGL); União Econômica e Aduaneira da África Ocidental (UEMOA); Comunidade Econômica e Monetária da África Central (CEMAC); e Comissão do Oceano Índico (IOC). O critério utilizado pela UA inclui todos os Estados do continente africano, evitando a superposição excessiva de CER.
} 
integração, apesar do relativamente baixo nível de sucesso. Criadas em 1975, 1999 e 1992 respectivamente, a ECOWAS (Economic Community of West African States), a EAC (East African Community) e a SADC (Southern African Development Community) são as CER em estágio mais avançado de integração ${ }^{18}$.

Porém o grande número de CER cria problemas para a integração, tornando difícil o estabelecimento de taxas comuns, já que a participação dos países em mais de uma comunidade inviabiliza as medidas tomadas no âmbito regional. Problemas como barreiras não tarifárias, corrupção de funcionários e bloqueios policiais são fatores dificultadores (RODRIGUES; CAPUTO, 2013, p.113).

O objetivo da união econômica é a redução dos custos de exportação/importação estimulando assim o comércio intra-africano, por meio da redução/eliminação de barreiras alfandegárias. Isso promoveria uma maior independência em relação ao Ocidente ou ao norte global e aceleração do desenvolvimento. Os ganhos proporcionados por investimentos nos setores produtivos são maiores ao se investir em escala continental, gerando benefícios como: 1) diversificação econômica; 2) redução da dependência de exportação de commodities; 3) aumento da competitividade (RODRIGUES; CAPUTO, 2013). A complexidade e a necessidade de um esforço contínuo de coordenação que a tarefa de integração continental requer, faz com que uma instituição como a UA seja bastante útil e os projetos da Agenda 2063 vão nesta direção.

\section{Agenda África 2063: “A África que nós queremos"}

Mais do que apenas uma lista de desejos para o futuro, a Agenda África 2063 traz em seus documentos uma série de projetos que deverão alçar o continente a um patamar de desenvolvimento econômico-social maior. O projeto da Agenda seria diferente dos demais projetos pensados para o continente devido à "abordagem de cima para baixo" ${ }^{19}$, orientação para resultados, monitoração e avaliação, coerência de políticas e redefinição dos

\footnotetext{
${ }^{18}$ Apesar de em 1980 ter sido criada a Southern African Development Coordinating Conference (SADCC), apenas em 1992 é criada uma associação com um "arranjo juridicamente vinculativo". Disponível em: $<$ https://www.sadc.int/about-sadc/overview/>. Acesso em 18/05/2019

${ }^{19}$ No original, bottom-up approach, significa que no projeto da Agenda 2063 a tomada de decisões é descentralizada e valoriza a participação popular.
} 
financiamentos/parcerias (AFRICAN UNION, 2015, p. 5). Alguns dos Flagship Programmes que integram a Agenda são ${ }^{20}$ :

Formulação de uma estratégia de commodities.

Criação de uma universidade virtual.

Silenciar as armas até 2020 .

Criação de um passaporte africano.

Estabelecimento de uma Zona de Livre Comércio Continental.

Desenvolvida por meio de uma parceria entre a Comissão da União Africana (AUF), a Agência de Planeamento e Coordenação (NPCA) da NEPAD $^{21}$ e em colaboração com o Banco Africano de Desenvolvimento (AfDB) e a Comissão Econômica das Nações Unidas para África (UNECA), a Agenda é definida pela União Africana como

(...) o plano mestre para transformar a África na potência global do futuro. É o marco estratégico do continente, que visa cumprir sua meta de desenvolvimento inclusivo e sustentável, e é uma manifestação concreta do impulso Pan-africano pela unidade, autodeterminação, liberdade, progresso e prosperidade coletiva perseguidos no contexto do Pan-africanismo e do Renascimento Africano ${ }^{22}$.

Isto é, a Agenda é um quadro de estratégias baseadas em projetos novos e já existentes com um viés de integração continental, buscando o desenvolvimento total do potencial econômico e social do continente africano. A Agenda define áreas chaves para onde devem se voltar os investimentos dos Estados, além de definir as fontes dos recursos e estabelecer metas de curto, médio e longo prazo.

\footnotetext{
20 São 11 Flagship Programmes ao todo. AFRICAN UNION. The Key Agenda 2063 Flagship Programmes Projects

21 "A Nova Parceria para o Desenvolvimento da África (NEPAD) é um documento oficial adotado pelos chefes de Estado e de Governo africanos, em outubro de 2001, em Abuja, capital da Nigéria. Esse documento apresenta os objetivos do NEPAD como uma promessa feita pelos dirigentes africanos, fundada numa visão comum, assim como uma convicção firme e compartilhada, fazendo com que haja urgência para erradicar a pobreza, colocar os países, individual e coletivamente na via de um crescimento e de um desenvolvimento duradouros, participando ativamente na economia e na política mundial" (DIALLO, 2006, p. 64)

${ }^{22}$ Original: AGENDA 2063 is Africa's blueprint and master plan for transforming Africa into the global powerhouse of the future. The continent's strategic framework aims to deliver on its goal for inclusive and sustainable development and is a concrete manifestation of the pan-African drive for unity, self-determination, freedom, progress and collective prosperity pursued under Pan-Africanism and African Renaissance. Disponível em: <https://au.int/en/agenda2063/overview>. Acesso em 01/07/2019
} 
A Agenda é composta por vários documentos, sendo os principais o Documento Base da Agenda África 2063, sua versão popular e o Primeiro Plano Decenal de Implementação ${ }^{23}$. A linguagem adotada em todos os documentos é extremamente influenciada pelos ideais Pan-africanos e por um perceptível otimismo, como é explicitado no exemplo do "E-mail do futuro", escrito a um hipotético Kwame Nkrumah no ano de 2063. Redigido pela Presidente da Comissão da União Africana, Dr. Nkosazana Dlamini Zuma, durante a reunião ministerial do Conselho Executivo da União Africana em Bahir Dar, Etiópia, o “e-mail” traz uma visão do futuro desejado para o continente, e como ele foi alcançado. A ênfase do texto está na promoção da diversidade, desenvolvimento agrícola até a autossuficiência, autofinanciamento e união Pan-africana em uma confederação de Estados. Esses seriam os elementos responsáveis pela transformação do continente (ZUMA, 2014).

Citando Nkrumah e o ideal central do Pan-africanismo, a união política de todos os países africanos em uma única entidade, Zuma escreve que em 2063 a união é uma realidade. A justificativa para unificação se concentra principalmente na fragilidade político-econômica que os 55 Estados soberanos representam atualmente, fragilidade que se extinguiria com a criação da terceira maior economia do mundo, em 2063, que se tornaria realidade com a criação da confederação (ZUMA, 2014, p. 1).

A transformação do continente viria por meio de investimento africanos e internacionais, priorizando investimentos africanos e de países do BRIC ${ }^{24}$. Zuma faz uma crítica aos "eufemisticamente chamados parceiros", os doadores dos programas de ajuda e investimentos que no passado, e no presente, atuam sobre o continente. Além disso, investimentos pesados em educação e valorização das formas tradicionais de produção agrícola gerariam uma revolução agrária. Investimentos na "economia Azul" 25 seria um dos pilares mais importantes do aceleramento do desenvolvimento. O resultado dessas medidas seria, além de alçar o continente ao posto de terceira maior economia do mundo, obter um assento permanente no Conselho de Segurança da ONU, a substituição das atuais línguas europeias atualmente usadas pela maioria da população africana pelo KiSwahili, enfim, a solução definitiva para os problemas no continente. Independente da factibilidade ou não da

\footnotetext{
${ }^{23}$ AFRICAN UNION. Background Note. 2015, Disponível em: <https://au.int/en/agenda2063/overview>. Acesso em 01/07/2019

${ }^{24}$ A presidente Zuma usa em seu "e-mail" o termo BRIC, Apesar da entrada África do Sul em 2011 no grupo que reúne as principais economias em desenvolvimento do mundo, mudando a sigla para BRICS.

${ }^{25} \mathrm{~A}$ economia azul seria a reunião de todos os elementos produtivos encontrados nos oceanos, desde frutos do mar até o petróleo.
} 
visão de futuro expressa pela presidente, o que fica evidente é, além do otimismo exacerbado, a constante presença de ideais Pan-africanos e o desejo de que os africanos, sobretudo mulheres e jovens, se tornem protagonistas de sua história e agentes do progresso africano. A questão identitária dos africanos no continente e na diáspora, bastante cara para os primeiros pan-africanistas, também se faz presente, e como arremate do "e-mail", Zuma escreve sobre as conversas para a criação da Confederação dos Estados Africanos e do Caribe (ZUMA, 2014, p. 7).

Não só no "e-mail" da presidente Zuma, mas por todo o texto dos documentos da Agenda são recorrentes vários exemplos da influência dos ideais Pan-africanos, sobretudo na segunda e na quinta aspirações ${ }^{26}$. Tratando respectivamente de aspectos políticos e culturais, essas aspirações possuem influências diretas dos textos dos líderes dos movimentos identitários que influenciaram as conquistas das independências na década de 1960.

A segunda e mais delicada aspiração da Agenda 2063 traz logo em seu título a fonte de sua inspiração: “Um continente integrado, politicamente unido e baseado nos ideais do Pan-africanismo e na visão do Renascimento Africano”. Assim como Nkrumah em 1963 propôs à unificação do continente em uma única entidade, como forma de alcançar seu pleno desenvolvimento, combater o imperialismo e consolidar as independências, os líderes africanos signatários dos projetos da Agenda consideram a união como alternativa para a África.

Já o desejo expresso por Zuma de usar o KiSwahili como língua franca do continente é bastante ilustrativo de como as questões identitárias são vistas pela União Africana e aproximam-se das teses Pan-africanas: "Uma África com forte identidade cultural, patrimônio comum, valores compartilhados e ética". A redução do uso de línguas europeias em favor de uma língua africana, atualmente a terceira em número de falantes depois do inglês e do árabe, é uma tentativa de criar uma maior coesão entre os 55 países, que possuem diferenças socioculturais enormes, sendo um dos maiores desafios da hipotética Confederação de Estados Africanos e a quinta aspiração da Agenda.

\footnotetext{
${ }^{26}$ A Agenda é composta por sete aspirações gerais: 1. Uma África próspera baseada no crescimento inclusivo e desenvolvimento sustentável; 2. Um continente integrado, politicamente unido e baseado nos ideais do pan-africanismo e a visão do Renascimento Africano; 3. Uma África de boa governança, democracia, respeito pelos direitos humanos, justiça e estado de direito; 4. Uma África pacífica e segura; 5. Uma África com forte identidade cultural, patrimônio comum, valores compartilhados e ética; 6. Uma África cujo desenvolvimento é orientado para as pessoas, contando com o potencial dos povos africanos, especialmente suas mulheres e jovens e cuidado das crianças; 7. África como uma comunidade global forte, unida, resiliente e influente jogador e parceiro. (AFRICAN UNION, 2015, p. 2)
} 


\section{Agenda 2063 aplicada}

O tom de otimismo muda quando se é analisado a implementação das medidas mais efetivas para o continente proposta pela Agenda, como a Zona de Livre Comércio. Apesar de ter sido assinado por 52 países, o acordo foi ratificado por apenas 22 membros $^{27}$, e ainda não inclui Eritreia, Benin e Nigéria - o que gera maiores inquietações ${ }^{28}$.

Uma das primeiras e principais medidas que compõem os Flagship Programmes da Agenda 2063, a criação de uma zona de livre comércio, é um significativo passo em direção ao estabelecimento da Confederação Africana de Estados à qual se refere a Dr. Nkosazana Zuma. Criada com o propósito de impulsionar o comércio intra-africano, a Zona de Livre Comércio pode ser um indicador prematuro das dificuldades e do sucesso da Agenda 2063.

O exemplo da Nigéria em relação ao acordo de livre comércio demonstra os impasses a que a desejada união política africana estará exposta. As diversas agências governamentais e privadas nigerianas possuem interesses que podem ou não ser atendidos com o fim dos impostos de importação/exportação. As preocupações protecionistas se sobrepuseram às demais no caso da Nigéria, e a maior economia do continente, apesar da pressão dos vizinhos, ainda não ratificou um acordo dessa magnitude.

Além da ausência da Nigéria no acordo, o fato de que próximo à data de implementação da zona de livre comércio apenas 22 países o ratificaram ${ }^{29}$, o mínimo exigido para a que ela tenha início, o que pode ser preocupante e levantar questões quanto à efetividade e interesse dos países em aderir aos Flagship Programmes da Agenda.

Com lançamento simbólico na reunião do jubileu das independências em Addis Abeba e com implantação programada para 2020, o passaporte da União Africana é outra medida chave para o sucesso da Agenda. Apesar da existência do Tratado de Abuja (1991), que estabelece, em outras coisas, a livre movimentação e direito de residência para os

\footnotetext{
${ }^{27} \mathrm{O}$ acordo tinha como pré-requisito a assinatura de 22 países. Para alcançar esse número, contaram com a República Saharaui. Os demais membros que ratificaram o acordo são: África do Sul, Chade, Costa do Marfim, Djibouti, Egito, Etiópia, Gâmbia, Gana, Guiné, Mali, Mauritânia, Namíbia, Níger, Quênia, República do Congo, Ruanda, Senegal, Serra Leoa, Togo e Uganda. AFRICAN UNION. Agreement secures minimum threshold of 22 ratification as Sierra Leone and the Sahrawi Republic deposit instruments. 2019

${ }^{28}$ African Union urges Nigeria to join new trade zone. Disponível em:

$<$ https://www.ft.com/content/b1d880a2-723b-11e9-bf5c-6eeb837566c5> Acesso em 01. Jul.2019

${ }^{29}$ Apesar disso, 52 países africanos assinaram o acordo. As exceções são Nigéria, Eritreia e Benin. AFRICAN UNION. TREATY ESTABLISHING THE AFRICAN ECONOMIC COMMUNITY
} 
cidadãos que fazem parte da comunidade, houve poucos avanços nesse sentido. A implantação de um passaporte que torne possível a livre movimentação entre os cidadãos dos países-membros pode ser uma das medidas mais importantes, tanto social como economicamente para um continente recortado em 55 unidades políticas.

Segundo o Africa Visa Openness Report 2016, apenas 13 países africanos não exigem vistos de entrada para todos os cidadãos africanos ${ }^{30}$. Isso limita, em vários aspectos, o desenvolvimento e a integração de um continente que conta com mais de 600 fronteiras políticas. Considerando a imigração como algo positivo e necessário para a economia da África, essa medida tornaria ainda mais fácil os deslocamentos humanos, aumentando a integração e criando um sentimento de unidade, indispensável em um projeto de união política (AFRICAN DEVELOPMENT BANK, 2016, p. 25).

No relatório são apresentados dois estudos de caso, Ruanda e Ilhas Maurício, em que o fim de exigências de visto teve consequências extremamente positivas nos dois países, sobretudo nas áreas de viagens e turismo. Houve um salto no número de visitantes africanos em ambos os países, o que contribuiu para melhorar os índices de investimento e facilitou o preenchimento de vagas de trabalho ociosas (AFRICAN DEVELOPMENT BANK. 2016, p. 19-20).

O fim da necessidade de visto é ao mesmo tempo necessário para a realização dos objetivos que compõem a segunda aspiração da Agenda África 2063, e um passo em direção à integração. Aliada à zona de livre comércio a ser implementada ainda em 2019, pode significar o começo de uma revolução no continente, a partir da qual os países africanos se voltariam a si mesmos para encontrar as soluções de desenvolvimento e não mais para o exterior.

\section{Conclusão}

Independente de quão efetivo ou ideal para a resolução das questões que se impõem ao continente africano no século XXI, é explícito o fato de que as teorias identitárias desenvolvidas na África, Pan-africanismo e Nègritude, ainda se mantêm vivas na mentalidade

\footnotetext{
${ }^{30} \mathrm{Na}$ verdade, apenas Seychelles não exige nenhum tipo de visto. Os outros 12 países (Madagascar, Comoros, Burundi, Rwanda, Maurício, Moçambique, Mauritânia, Guiné-Bissau Togo Cabo Verde, Uganda e Mali) oferecem o visto no desembarque.
} 
de vários líderes africanos. A Agenda África 2063 é o maior exemplo disso, ao trazer em seu corpo vários ideais e conceitos originários dessas correntes. Os intelectuais africanos, notadamente Nkrumah e Senghor, possuem um papel enorme no sentido de que, mesmo não tendo conseguido materializar suas teorias em vida, são os responsáveis por criar os parâmetros da solução africana para a África, apesar das críticas que suas visões de mundo recebam.

O ideal de integração continental é discutido por vários teóricos e políticos. O desejo de que o desenvolvimento africano seja dirigido pelos próprios africanos é antigo e chega com força total ao presente. Isso pode representar uma tentativa de ruptura com o que Mbembe chamou de vitimização, dado que na Agenda 2063, os africanos serão os protagonistas em todos os aspectos.

Assim como na época das independências, um otimismo baseado no rápido nível de crescimento observado em grande parte dos Estados africanos se observa no presente, gerando novas esperanças para o continente. A renovação do otimismo parece vir acompanhada de um renascimento das teorias originais para se pensar África. Essas teorias, apesar de passíveis de críticas, são incontornáveis e fornecem um instrumental altamente influente nas políticas pensadas para o continente.

O consenso existente sobre a necessidade africana de integração tem uma oportunidade de finalmente se materializar (RODRIGUES; CAPUTO, 2014, p.119). E tudo indica que será sob os ideais Pan-africanos.

\section{Bibliografia}

AFRICAN UNION AGENDA 2063. A Shared Strategic Framework for Inclusive Growth and Sustainable Development - Background Note. Addis Ababa, African Union, Aug. 2013.

ANGLARILL, Nilda Beatriz. Construcción Democrática y Gobernabilidad en África. Lisboa, 1998.

BINEY, Ama, Nkrumah and the Opposition, 1954- 1957. In.: The Political and Social thought of Kwame Nkrumah. 2011.

HOUPHOUET-BOIGNY, Felix. Black Africa and the French Union. in.: Foreign Affairs, Vol. 35, No. 4 (Jul., 1957), pp. 593-599 
JAMES, C.L.R. Black Power: its Past,Today and the Way Ahead', in C.L.R. James, Spheres of Existence. Selected Writings, Allison and Busby, London.1980.

KIRK-GREENE, A.H.M. West Africa: Nigeria and Ghana. In: Politics \& Government in African States. 1986.

MARTIN, Guy. African Political Thought. New York. 2012.

MBEMBE, Achille. As formas africanas de auto-inscrição. Estud. afro-asiáticos. [online]. 2001, vol.23, n.1, pp.171-209

GAUFRYAU, Bertrand; MALDONADO, Carlos. « secteur informel : fonctions macro-économiques et politiques gouvernementales: le cas de la côte d'ivoire » [archive], sur le site de l'OIT. 1998.

NANTAMBU, Kwame. Pan-Africanism Versus Pan-African Nationalism: An Afrocentric Analysis, Journal of Black Studies, Vol. 28, No. 5 (May, 1998), p. 561-574.

NKRUMAH, Kwame. Africa Must Unite. New York: Frederick A. Praeger. 1963.

PENNA FILHO, Pio. A África Contemporânea: do colonialismo aos dias atuais. Brasília: Hinterlândia Editorial. 2009.

RODRIGUES, Denise Andrade; CAPUTO, Ana Cláudia. O projeto de integração da África: aspectos físicos, comerciais, financeiros $\mathrm{e}$ de investimento. Disponível em: http://www.bndes.gov.br/bibliotecadigital

SARAIVA, José Flávio S. A África no século XXI: um ensaio acadêmico.Brasília. 2015.

SHERWOOD, Marika. Manchester and the 1945 Pan African Congress. 1995.

SCHMIDT, Elizabeth. Foreign Intervention in Africa: From the Cold War to the War on Terror. 2013. 


\section{PAN-AFRICAN CONFERENCE.}

WESTMINSTER TOWN HALL,

ON THE

23rd, 24th and 25th JULY, 1900.

This Conference is organised by a Committee of the African Association for the Discussion of the "Native Races" Question, and will be atiended and addressed by those of African descent from all parts of the British Empire, the United States of America, Abyssinia, Liberia, Hayti, etc.

YOU ARE CORDIALLY AND EARNESTLY INVITED TO ATTEND.

CONFERENCES-Morning, ro.30 and Evening, 8.

H. S. Williams, Hon. Sec.,

I39, Palace Chambers, S. W. 
ANEXO 2 - MAPA DA FEDERAÇÃO AFRICANA DE ESTADOS PROPOSTA POR MUENI WA MUIU E GUY MARTIN

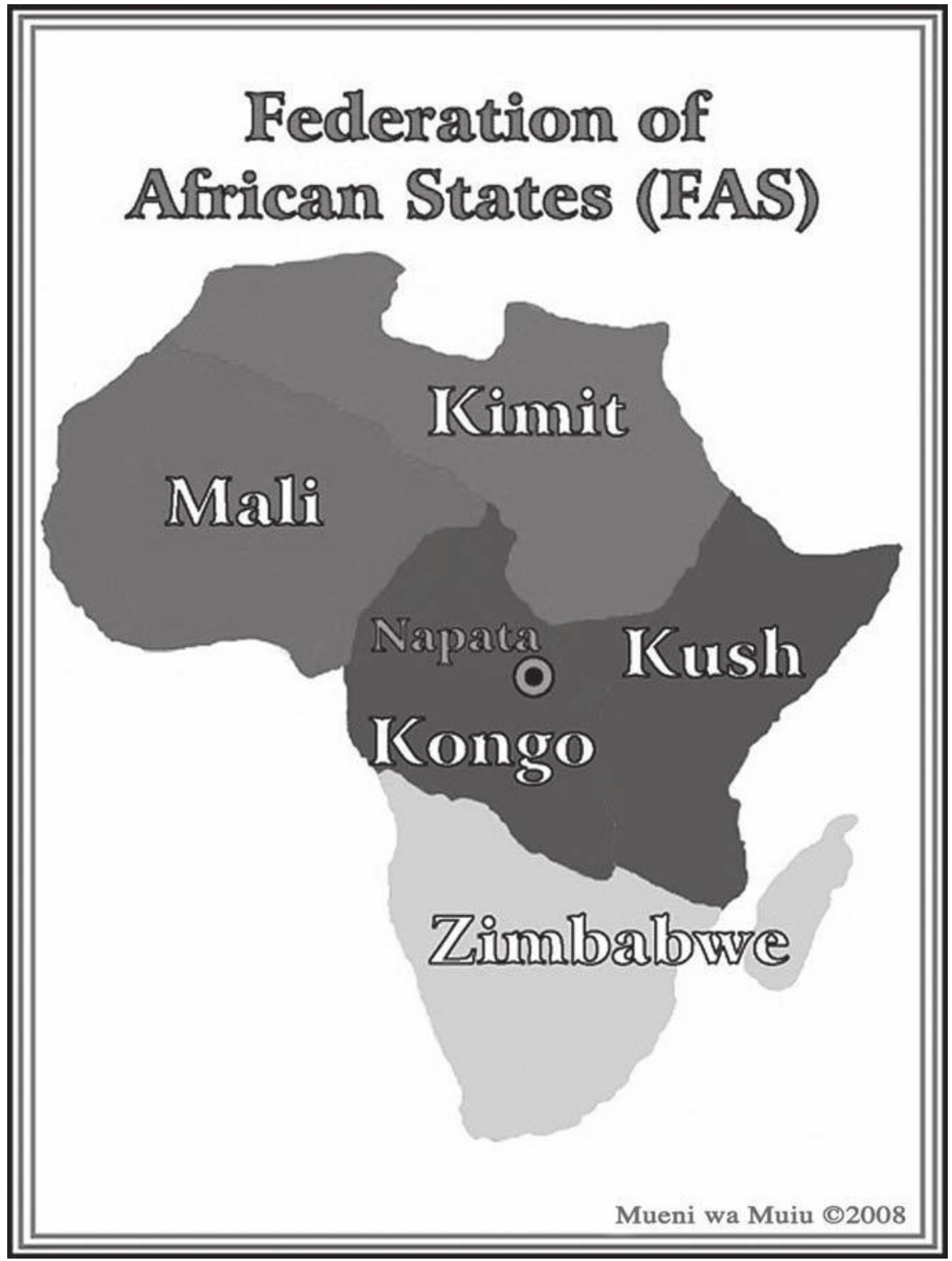

